\title{
Percepção ambiental de estudantes sobre seu bairro
}

\section{Environmental perception of students about the neighborhood where they live and study}

\author{
Percepción ambiental de los estudiantes sobre el barrio en el \\ que viven y estudian
}

\section{Lorena Macêdo A. N. de Oliveira*}

Universidade Federal do Rio Grande do Norte - UFRN, Natal, Rio Grande do Norte, Brasil

\section{Larissa Maria de Menezes Costa**}

Universidade Federal do Rio Grande do Norte - UFRN, Natal, Rio Grande do Norte, Brasil

\section{Gleice Azambuja Elali***}

Universidade Federal do Rio Grande do Norte - UFRN, Natal, Rio Grande do Norte, Brasil

\begin{abstract}
RESUMO
As políticas brasileiras, no campo da educação, estimulam a relação escolabairro como parte importante do processo educativo, para o que entendemos ser fundamental valorizar tanto as características do ambiente sócio físico, quanto a experiência das pessoas que ali convivem. Com base nesse quadro geral, investigamos a percepção dos estudantes sobre os locais onde moram e estudam, explorando os limites do bairro e como situam a escola nesse contexto. Metodologicamente foram utilizados diários pessoais com solicitação do desenho de mapas e entrevistas realizadas durante caminhadas pela área. Participaram 23 estudantes (15 mulheres e 7 homens), com idades entre 13 e 17 anos, matriculados no 9o ano do ensino fundamental de uma escola pública do bairro Guarapes, Natal-RN. Os resultados mostram sua percepção sobre a setorização do espaço, a predominância de descrições gráficas relativas ao centro do bairro e dificuldades no reconhecimento de mudanças previstas para acontecerem naquela zona urbana.
\end{abstract}

Palavras-chave: relação escola-bairro, percepção ambiental, estudantes.

\section{ABSTRACT}

Brazil's policies in the field of education encourage school-community relathionship as an important part of the educational process, for which we believe is essential to valorise both the physical characteristics of the social environment and the experience of the people who live there. Based on this, we investigate the perception of students about where they live and study, exploring the boundaries of the local and how to place the school in this context. Methodologically they were used diary personal with drawing maps 
and interviews during walks in the area. There were 23 students ( 15 women and 7 men) aged between 13 and 17 years enrolled in the 9th grade in a public school Guarapes neighborhood, Natal-RN. The results show their perception of the compartmentalization of space, the predominance of graphic descriptions of the center of the neighborhood and difficulties in recognizing changes set to take place in that urban area.

Keywords: school and community, environmental perception, students.

\begin{abstract}
RESUMEN
Políticas de Brasil en el campo de la educación fomentan la relacion escuelabarrio como una parte importante del proceso educativo, esencial para valorizar tanto las características físicas del entorno social y la experiencia de las personas que viven allí. Sobre este marco, se investiga la percepción de los estudiantes acerca de donde viven y estudian, la exploración de los límites del barrio y cómo colocar la escuela en este contexto. Metodológicamente fueron utilizados diarios personales con el dibujo de mapas y entrevistas durante los paseos en la zona. Había 23 estudiantes (15 mujeres y 7 hombres) con edades entre los 13 y 17 años matriculados en el noveno grado en una escuela pública situado en barrio Guarapes, Natal-RN. Los resultados muestran la compartimentación del espacio, el predominio de las descripciones gráficas del centro de la zona y las dificultades para reconocer los cambios que tendrá lugar en esa zona urbana.
\end{abstract}

Palabras clave: relación escuela-barrio, percepción ambiental, estudiantes.

\title{
1 Introdução
}

No Brasil, o Movimento das Cidades Educadoras influenciou uma série de iniciativas no campo educacional, visando promover a educação integral e a aproximação entre escola e bairro por meio de projetos, debates e intervenções (Singer, 2015). A literatura identifica diversas iniciativas oficiais consideradas como marcos relativos à educação integral, com base nas quais, o Plano Nacional de Educação - PNE (Ministério da Educação, 2013a) ressaltou, entre suas prioridades, a valorização da experiência extraescolar do aluno e a necessidade de adequar o Projeto Político Pedagógico das escolas ao contexto no qual estão situadas. Com relação a este último aspecto, o Manual de Educação Integral (MEC, 2014), indicou a importância da relação escola-comunidade como estratégia para fortalecer e estreitar parceria entre ambos, contribuindo para a diminuição de índices de violência, sobretudo aquelas instituições localizadas em regiões de risco e dificuldade/ausência do acesso a serviços de garantia de direitos.

Apesar dessa evidente ênfase na aproximação entre a escola, o contexto em que ela se insere e o público para o qual suas ações se destinam, pesquisadores nesse campo apontam dificuldades sobre aspectos relacionados à implantação de programas dessa natureza (Santos, 2002; Silva, 2009; Stoco \& Almeida, 2011), notadamente na compreensão do espaço público de direito (Faria, 2011). 
Partindo desse quadro foi realizado um estudo cujo objetivo geral explorou as percepções dos estudantes que moram e estudam no Guarapes (bairro periférico de Natal-RN) sobre a relação entre estes dois ambientes. Especificamente buscou-se investigar as percepções dos estudantes a respeito do bairro, seu conhecimento sobre 0 mesmo e sobre as atividades que ali acontecem.

A investigação teve como base a Psicologia Ambiental, área de conhecimento que investiga os modos de relacionamento entre as pessoas e seus ambientes (Bonnes \& Sechiarolli, 1995), cujo "foco da análise está nas inter-relações entre pessoas e seus meios sócios físicos" (Stokols, 1978, p. 33-34). Neste campo admite-se o ambiente como multidimensional, envolvendo o meio físico (natural ou construído) e as pessoas que ali se encontram, além de atrelado às circunstâncias sociais, econômicas, políticas, culturais e psicológicas existentes. Ou seja, a configuração do ambiente "é dinâmica e unitária, incorporando mudanças que são assimiladas pelo ambiente como um todo" (Campos-de-Carvalho, Cavalcante \& Nóbrega, 2010, p. 28). Dentre as investigações realizadas nesse campo destacam-se aquelas sobre a percepção ambiental, foco do estudo realizado.

Este artigo é um recorte de uma pesquisa de mestrado mais ampla que investigou a relação escola-bairro em área periférica de uma metrópole no nordeste brasileiro sob o ponto de vista de estudantes que finalizavam o estudo fundamental (Oliveira, 2016), e cuja pesquisa empírica utilizou multimétodos (ver detalhamento em item específico). Ele discute a percepção e limites do bairro sob o ponto do grupo participante, sendo tais itens entendidos como indícios da relação escola-bairro admitida no estudo mais abrangente.

\subsection{Princípios que orientam a discussão}

Referindo-se à pesquisa em ambiente escolar, Rivlin e Weinstein (1984) salientaram a importância de investigar cuidadosamente o espaço físico, indicando que profissionais e estudiosos da área educacional geralmente desconsideram o caráter físico de escolas, bem como a influência do ambiente no comportamento e no "programa educacional" (Rivlin \& Weistein, 1984, p. 348), embora a conscientização sobre estes aspectos possa possibilitar maior qualidade à educação, ampliando a consistência das experiências vivenciadas pelos estudantes (crianças, adolescentes e jovens).

Sob perspectiva semelhante, ao investigar a relação entre crianças e ambientes escolares Gump (1978) advertiu sobre a importância da articulação de três domínios: a função do ambiente, os estímulos existentes e as mudanças no desenvolvimento. Dentre tais domínios o autor ressaltou que as variáveis menos trabalhadas são aquelas relativas ao ambiente, apesar de sua grande influência sobre 0 comportamento humano (potencializando-o ou prejudicando-o). 
Portanto, ao tomar o ambiente escolar como ponto de partida para um estudo é essencial considerar tanto os seus aspectos físicos quanto as questões sociais que o envolvem.

Ao discutirem a relação entre características do bairro e o desempenho dos estudantes de escolas municipais situadas em zonas de vulnerabilidade social da cidade de Campinas/SP, Stoco e Almeida (2011, p. 665) indicaram a necessidade de atenção a indivíduos ou grupos que "enfrentam riscos e impossibilidade de acesso a serviços e direitos básicos de cidadania, como condições habitacionais, sanitárias, educacionais, de trabalho e de participação e acesso à informação e às oportunidades", sobretudo quando a oferta destes mesmos itens para outras pessoas/grupos é, comparativamente, mais ampla. Partindo desse entendimento, foram trabalhados as noções de segregação espacial (restrição espacial de uma população por limitação de mobilidade), efeito vizinhança (consequência das relações estabelecidas no local de moradia sobre situações ocorridas na vizinhança) e efeito escola (fatores concentrados na escola que influenciem o desempenho de alunos), e os autores evidenciaram a necessidade de estudos que "compreendam de maneira abrangente os fatores que influenciam o desempenho nas escolas, a partir de noções promissoras, que evidenciem o contexto social no qual o fenômeno circunscreve" (Stoco \& Almeida, 2011, p. 669), em especial quando associados a uma metodologia qualitativa.

Assim, entendendo-se que o imaginário sobre bairros pode repercutir sobre a convivência de seus habitantes, é fundamental discutir a forma como se estabelece a inserção daqueles que neles residem. Nesse campo, Moreno (2010) enfatizou a importância de abordagens que, mesmo focados nos integrantes da escola, extrapolem o espaço da instituição e de sua vizinhança imediata, valorizando símbolos e códigos territoriais como orientadores da experiência social dessas pessoas. O estudo da autora em escolas da periferia analisou a presença de jovens em espaços sociais, assumindo como estratégia investigativa "a observação direta de campo sobre os espaços que conformam suas redes de reciprocidade, seus circuitos e trajetos" (Moreno, 2010, p. 189).

Também analisando trajetos de jovens em um bairro periférico, Albino (2002) acessou a percepção de alunos do ensino médio da rede pública de Mãe Luísa, região metropolitana do Natal-RN, discutindo modos de mobiliza-los sobre formas de envolver-se com o planejamento e gestão do bairro. O autor destacou a representação de espaços com maior valor afetivo e detectou representação e apropriação diferenciada entre gêneros.

Por sua vez, Günther, Nepomuceno, Spehar e Günther (2003) investigaram lugares preferidos e não preferidos por estudantes de Brasília-DF. Nesse conjunto, casa, shopping e áreas verdes destacaram-se entre os favoritos, enquanto, entre os lugares menos- 
favoritos, os alunos de escolas públicas destacaram em segundo lugar a escola e em primeiro a vizinhança, que foi apontada em associação à problemas de segurança pública.

Ao comentarem experiências em escolas inglesas que, inspiradas na iniciativa Building Schools for the Future (BBC, 2011), buscavam uma transformação educacional a partir de, entre outros, o maior uso da escola pela comunidade, Leiringer e Caderlino (2011) ressaltam a importância de ampliar o debate sobre o ambiente físico e design da escola, e sobre o modo como as facilidades existentes eram utilizadas e compreendidas pela população. O reconhecimento e valorização da opinião das pessoas que convivem na escola, e com a escola como base para intervenções nesse campo, amplia a necessidade de realização de trabalhos que focalizem a percepção ambiental, notadamente aqueles embasados na Psicologia Ambiental.

A noção de percepção ambiental traz em si a importância do ambiente em suas características físicas formais e simbólicas, por meio de um processo que se relaciona com as experiências, atitudes e visões de mundo das pessoas envolvidas (Tuan, 1980). Nesse campo, estudos realizados por Altman e Chemers (1980), Bonnes e Sechiarolli (1995), Hynek (1985), e Kuhnen e Higuchi (2011), entre outros, apontam a importância de investigar questões sociais e a cultura de grupos (considerados determinantes na aquisição de conhecimentos e de habilidades na utilização de espaços), bem como as relações que se estabelecem com estes e entre estes.

Sob o ponto de vista perceptivo, o ambiente sócio físico, além de ser produzido pelas pessoas, influencia suas representações, atitudes e ações, ou seja, o processo de codificação/ recodificação/memorização/uso das informações ambientais assume importante papel no desenvolvimento de atitudes e comportamentos relacionados aos ambientes (Altman \& Chemers, 1980; Siegel, Kirasic, \& White, 1978), bem como no processo de orientar-se e locomover-se no espaço. Ao estudar o papel orientador do espaço para discutir a legibilidade e imaginabilidade urbana, Lynch (1960/2011) identificou cinco elementos que compõem a imagem mental das cidades: vias (elementos que cortam o espaço e conduzem os deslocamentos das pessoas), limites (estruturas que definem fronteiras entre espaços), setores (partes menores do ambiente, decodificáveis pelos usuários), pontos nodais (locais de encontro, elementos que agregam pessoas), marcos (elementos físicos que se destacam na paisagem).

Deste modo, reconhecendo os elementos apontados pelos autores supracitados, esse texto discute os indícios sobre a percepção do bairro e seus limites sob a ótica dos estudantes, enquanto pessoa que tem a possibilidade de transitar livremente entre ambos. 


\section{Método}

O estudo aconteceu no bairro Guarapes, situado na cidade de Natal/RN, cuja área aproximada é de 865,95 hectares (ha) e comporta população de aproximadamente 11.334 habitantes, com densidade demográfica de 13,09 hab/ha, dispondo de 2.822 domicílios permanentes (Secretaria Municipal de Meio Ambiente e Urbanismo, 2015).

A investigação empírica utilizou multimétodos (Gunther, Elali, \& Pinheiro, 2008) envolvendo 3 etapas: 1- solicitação de diários acompanhados por mapas esquemáticos (Albino, 2002; Pinheiro, Elali, Azevedo, Farias, Costa \& Andrade, 2008), a fim de verificar como os estudantes percebem as relações estabelecidas entre 0 bairro e a escola, por meio de sua presença/ausência; 2- entrevistas individuais aliadas à caminhada no bairro, inspirada na estratégia de caminhada comunitária (Góis, 2007); 3- entrevista coletiva (Gaskell, 2002), utilizada como devolutiva. A análise das informações coletadas (textos e mapas dos diários, transcrições das falas gravadas durante as entrevistas) teve auxílio do software QDA Miner, baseado na análise de conteúdo temática (Flick, 2009). Embora cada uma das técnicas tenha gerado um conjunto de dados específicos, verificou-se grande semelhança entre tais informações, de modo que se optou por relatar os resultados a partir dos grandes temas que emergiram deste acervo: percepção e limites do bairro; usos dos espaços; acontecimentos envolvendo bairro e escola; relação bairro-escola; cotidiano do bairro. Este artigo explora temas e códigos que emergiram das análises dos diários e entrevistas, no que se refere ao primeiro dos pontos acima indicados (ou seja, características e limites do bairro percebidos pelos estudantes).

Participaram da primeira etapa de pesquisa 23 estudantes, com idades entre 13 e 18 anos, (todos matriculados regularmente no 9o ano do ensino fundamental, sendo 13 provenientes do turno matutino, e 10 do turno vespertino), dos quais 15 do sexo feminino e 7 do sexo masculino. Dentre eles, 16 aceitaram a continuidade da participação, 6 do turno matutino e 8 do vespertino, com idades entre 13 e 18 anos, sendo 10 do sexo feminino e 6 do masculino. Destas entrevistas 3 foram desconsideradas devido a prejuízos no áudio de gravação, sendo finalmente analisadas 13 entrevistas. Os pseudônimos adotados pelos participantes no diário foram considerados na análise das entrevistas dos 13 participantes que prosseguiram no estudo. A tabela 1 listada abaixo, apresenta a identificação fictícia, sexo, idade e turno, por estudante. 
Tabela 1.

Códigos de identificação dos participantes das etapas dos diários e entrevistas, e que constam como identificação na citação de dados por eles fornecidos

\begin{tabular}{|l|l|l|l|}
\hline $\begin{array}{l}\text { Entrevistado } \\
\text { (númerópseudônimo escolhido) }\end{array}$ & Sexo & Idade & Turno \\
\hline E1 - Pain & masc. & 16 & Matutino \\
\hline E2 - Kiba & masc. & 14 & Matutino \\
\hline E3 - Loreta & fem. & 14 & Matutino \\
\hline E4 - Esther & fem. & 14 & Matutino \\
\hline E5 - Oiac & masc. & 15 & Matutino \\
\hline E6 -Stephany. & fem. & 13 & Matutino \\
\hline E7 - Helisabeth & fem. & 15 & Vespertino \\
\hline E8 - Bélgica & fem. & 14 & Vespertino \\
\hline E9 - Magnólia & fem. & 15 & Vespertino \\
\hline E10 - Pâmela & fem. & 14 & Vespertino \\
\hline E11 - Tales & mas. & 15 & Vespertino \\
\hline E12 - Cristiano & masc. & 17 & Vespertino \\
\hline E13 - Sophia & fem. & 13 & Vespertino \\
\hline
\end{tabular}

A investigação seguiu as indicações da ética da pesquisa vigentes no Brasil, conforme a Resolução 446/12 do Conselho Nacional de Saúde / Ministério da Saúde. O projeto foi aprovado pelo Comitê de Ética em Pesquisa da Universidade Federal do Rio Grande do Norte. A participação dos estudantes foi voluntária, mediante adesão ao Termo de Consentimento Livre e Esclarecido (TCLE) dos Pais ou Responsáveis, em razão da faixa etária dos participantes; e ao Termo de Assentimento, relativo à participação e à gravação de voz.

\section{Resultados e discussão}

Os participantes descreveram características gerais do bairro e de locais específicos inseridos em seus limites, destacando seus aspectos sócio-físicos. Os desenhos obtidos foram classificados nas categorias: desenho de mapa (Figura 1), desenho artístico (Figura 2) e desenho de situação (Figura 3 ). O desenho de mapa corresponde a sistematização de espaços permitindo orientação dentro de um conjunto de elementos podendo assemelhar-se a descrição de uma rota (deslocamento no espaço). O desenho artístico inclui expressões de espaços por meio de elementos que extrapolam a localização, embora também possam assumir tal função. $O$ desenho de situação é um conjunto de expressões gráficas de um cenário de interação entre pessoas (representadas ou não). 


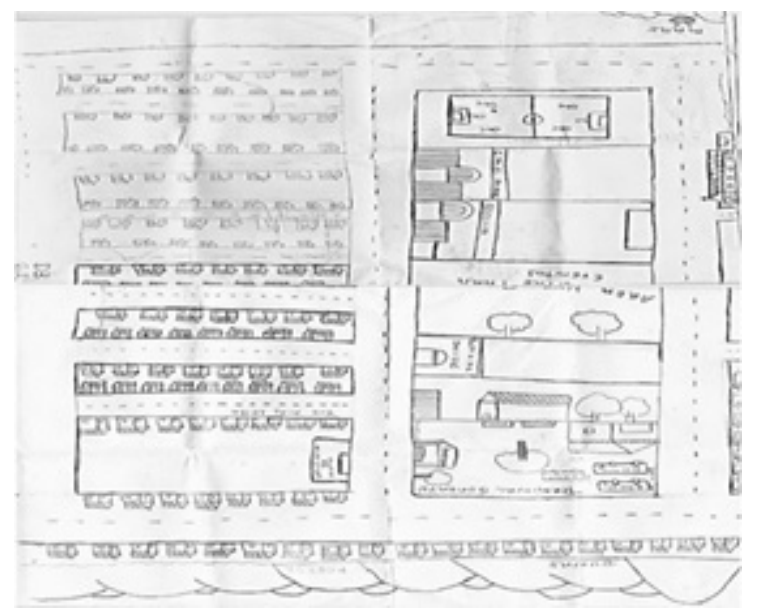

Figura 1. Desenho de mapa: apresentação do bairro (Estudante do turno vespertino, feminino, 17 anos)

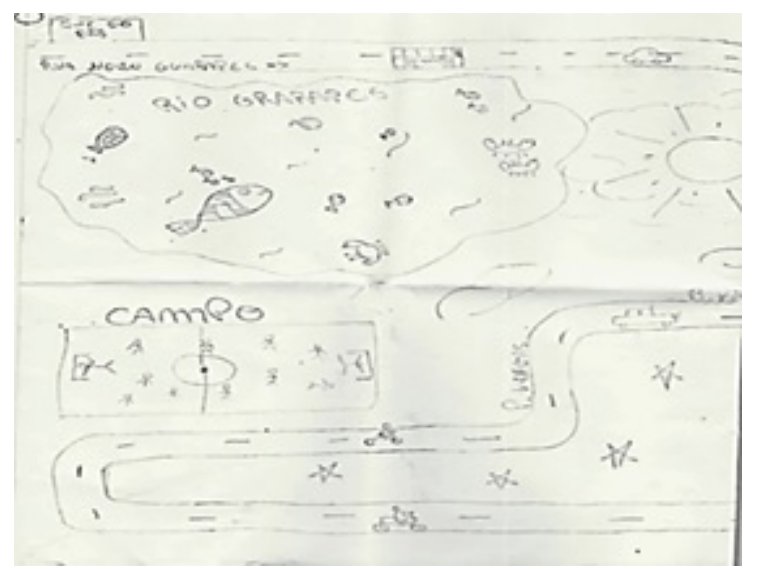

Figura 2. Desenho artístico do bairro: apresentação do bairro (Estudante do turno vespertino, feminino, 15 anos)

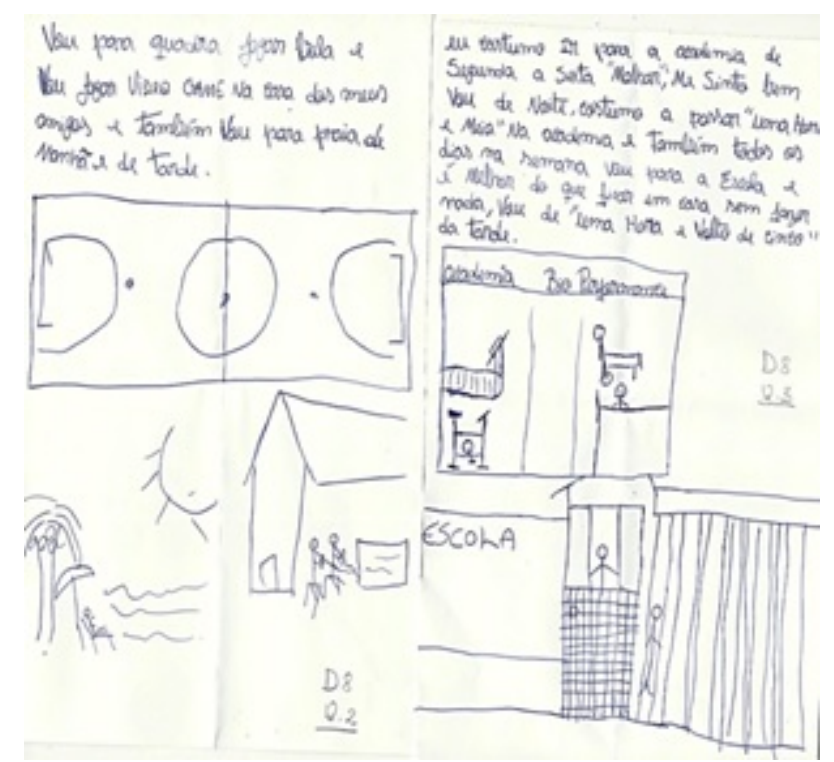

Figura 3. Desenho de situação: final de semana e dia de semana (Estudante do turno vespertino, masculino, 15 anos) 
Além do tema Tipologia dos desenhos, outros como Locais e Informações sobre o bairro, foram identificados a partir da análise dos diários. Mais temas também foram listados, os quais emergiram a partir dos conteúdos presentes nas respostas dos participantes à realização do diário e das entrevistas.

Unindo expressões gráficas e textos gerados nas questões dos diários, foi possível estimar agrupamentos de espaços inseridos no bairro, com base nas principais atividades para as quais são destinados. De um modo geral, nota-se predominância de vias (Ruas e Estradas), seguidas de Comércio, Serviços Públicos, Lazer, Áreas Residenciais, entre outros - e é possível localizar a maior parcela destes agrupamentos entre as proximidades da escola. Assim, comércio do bairro, praticamente toda a rede de serviços públicos, locais onde se dão atividades de lazer, e áreas residenciais, reúnem os ambientes mais referidos nos diários.

Inseridos no agrupamento "serviços públicos", destacam-se as menções à educação formal, totalizando 98 vezes, entre as quais 35 foram dedicadas a escola, na qual os participantes estudam. Nesse caso, a incidência de ambientes escolares constitui uma centralidade dentre os desenhos. Ainda que o bairro disponha de Centro de Referência em Assistência Social (CRAS) e uma Unidade de Saúde da Família (USF), este último destaca-se sobre o primeiro (com 12 menções, enquanto o outro teve apenas 1 ). Nota-se uma distribuição concentrada dos locais mencionados, em torno do chamado "centro", informação confirmada nas entrevistas. A partir de semelhança entre estes ambientes, foi possível agrupá-los em: lazer e esporte; espaços religiosos; espaços educacionais; pontos de ônibus; comércio e serviços; espaços públicos.

A apresentação do bairro por meio dos desenhos remete ao estudo de Lynch (1960/2011), sendo possível notar a presença de características que contribuem para a legibilidade do espaço, como o desalinhamento de quadras, mudanças abruptas das vias, cruzamento com vias de maior representação, entre outras. Nesta perspectiva, ressaltamos indícios atribuídos à percepção de cada aspecto do bairro pelos estudantes, como segue.

Inicialmente é preciso ressaltar que a área mais representada do bairro (ambientes mais frequentados pelos participantes) foi 0 chamado "centro", coincidentemente a área ao redor da escola, verificando-se considerável omissão das demais frações. Entre os principais limites indicados (Figura 4), destacam-se: as vias movimentadas (notadamente a Rua Novo Guarapes), e aquelas que separam o Guarapes de outros bairros. Ainda que vários elementos urbanos pudessem cumprir a função de limites e, ao mesmo tempo, garantir a manutenção da relação visual com outras áreas da cidade, atrair e unir habitantes, as delimitações indicadas não correspondem às fronteiras "oficiais" do Guarapes (segundo a legislação municipal - 
PMN, 2012). Se por um lado, as circunstâncias no modo de ver do observador, neste caso, dizem respeito a frequência de circulação que não abrange tais fronteiras, as características físicas podem auxiliar na demarcação do fim e do início de outra região. O bairro constitui-se delimitado por fronteiras que nem sempre foram apontadas pelos estudantes como limite físico correspondente. Exemplo disso é o Leningrado (antigo assentamento transformado em conjunto habitacional), que não parece ser identificado como porção no Guarapes, sendo apontado como pertencendo a outro bairro, o Planalto.

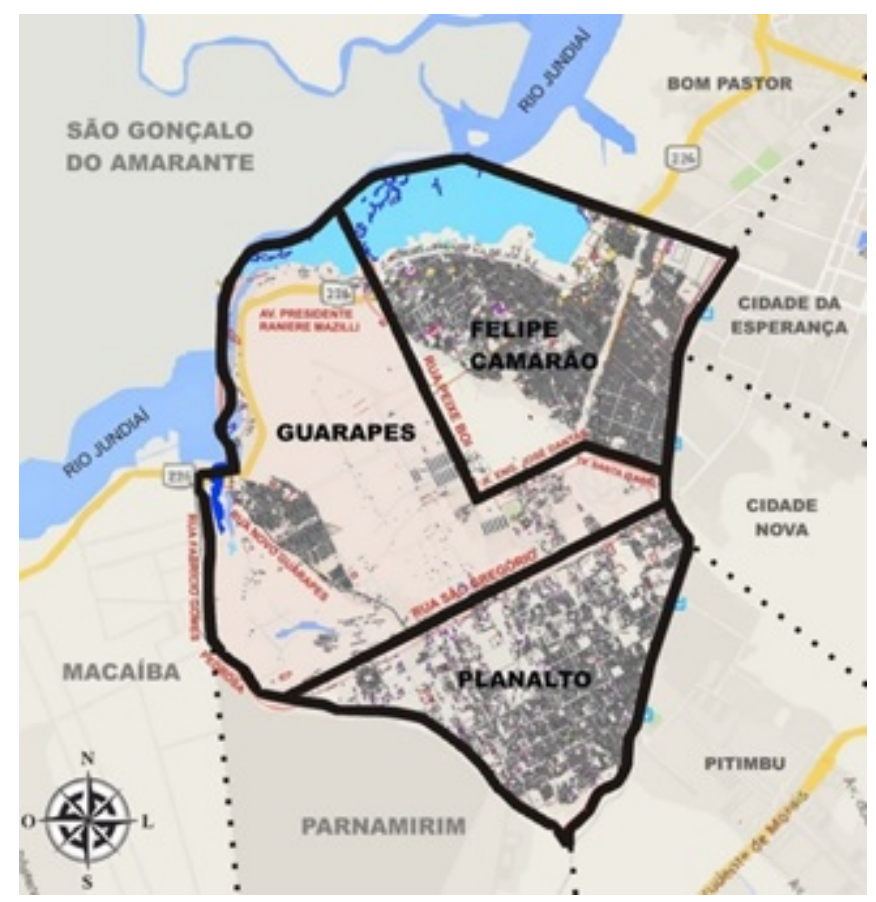

Figura 4. Localização da Rua Novo Guarapes e demais vias que delimitam o bairro

O bairro Guarapes possui ampla cadeia de dunas, compondo paisagens naturais com rio e área de mangue. No entanto, o agrupamento sobre ambientes naturais constituiu pouca representação quanto aos demais, sendo o morro (mencionado 5 vezes), a maré (mencionada 1 vez), e o Rio Guarapes (mencionado 3 vezes) situados, respectivamente, na proximidade de residências dos mesmos estudantes respondentes, e em pontos como a principal via de acesso ao bairro (rua Novo Guarapes). Em geral, paisagens são aspectos encontrados na apreciação dos locais, em descrições de suas características imagéticas, e percebidas nos desenhos de maneira abrangente (representação gráfica sem nomeação) e durante a realização de entrevistas.

Chama atenção, a ausência de menções sobre a instalação da Estação de Tratamento de Esgotos (ETE), cujo terreno previsto pode ser visualizado às margens de trecho da Rua Novo Guarapes (uma 
das principais vias de acesso ao bairro, de constante circulação dos estudantes). O fato é constantemente divulgado em redes sociais (blog de moradores, com notícias que já datam 2013, e persiste durante 2015, ano deste estudo em campo). Isso, pois o bairro abrange a ZPA4, além de rede hidrográfica banhada pelos rios Guarapes e Jundiaí, que permeiam os limites do bairro. Unido ao risco de comprometimento hidrográfico, tem seu patrimônio ecológico ameaçado, considerando as consequências para o equilíbrio ecológico do local. Portanto, indaga-se sobre o acesso às informações relativas às decisões impactantes e a efetividade deste acesso, visto que ainda coexiste a ideia sobre a boa qualidade e perenidade da água no bairro, explicitada em momento de discussão dos dados com os participantes por meio de afirmativas como "a água não vai acabar [...] aqui tem a melhor água de natal". Por tudo isso, como a população lida com essas decisões? Por que os participantes não mencionam sobre esta transformação eminente? A escola foi (e/ou é) espaço para este tipo de debate? Mesmo indagando sobre o local, parecem não identificar modificações nestas funções, as quais certamente serão parte de uma nova paisagem que ali vai surgir.

Os mapas indicaram não apenas a delimitação do centro, mas que existem outras setorizações do bairro, uma vez que, ao se referirem a áreas específicas, os participantes utilizaram expressões como "lá em baixo", "a maré", o "inferninho", entre outros. Tais indicações podem ser associadas ao que Lynch (2011, p.76) denomina "conotações sociais importantes", apontando para diferenciações de setores dentro do bairro, que podem representar conotações de classe e mesmo o surgimento de sub-bairros.

Em geral, os participantes aparentaram ignorar esse tipo de contradição em seus desenhos, que apenas eram aprofundadas quando questionadas nas entrevistas para devolutiva dos resultados. Além do estabelecimento das divisões, também foram identificadas avaliações de paisagens e locais específicos, qualidades, e informações gerais que complementam informações já evocadas em perguntas das entrevistas com caminhada no bairro, realizadas em momento anterior. No que se refere às áreas residenciais, apenas uma participante do turno vespertino menciona em seu diário o local denominado Leningrado, atual conjunto habitacional, nome que antes denominava um assentamento. O espaço está inserido nos limites do Guarapes, embora a estudante considere não fazer parte do mesmo. De modo semelhante ocorre com o Conjunto Dinarte Mariz que também se trata de local que concentra residências, conhecido pelos estudantes como "inferninho" (02 menções nos diários).

Portanto, com relação aos setores, ou porções do espaço ("lá em baixo", "aqui/lá em cima", "centro", entre outros), foram realizadas atribuições de características sócio físicas, que as distinguem uns dos outros. 
Quanto às vias, é importante ressaltar que as ruas mais representadas estão situadas em notável proximidade da escola. Semelhante às dificuldades na descrição de vias longas inseridas no espaço da cidade, é possível notar que muitas vias do bairro foram graficamente reduzidas pelos estudantes, como ocorre com a Rua Novo Guarapes (Figura 4) que, embora se estenda até zona limítrofe com outro bairro, tem representação limitada a trechos nas proximidades do ambiente escolar (Figura 5).

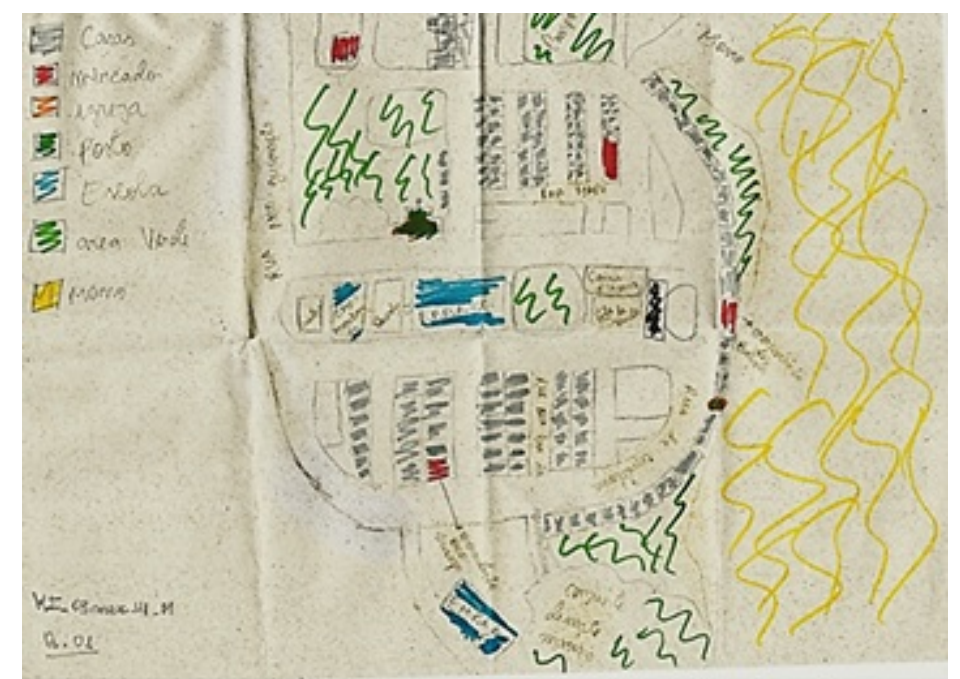

Figura 5. Desenho de mapa - apresentação do bairro (Estudante do turno matutino, masculino, 14 anos)

Os principais pontos nodais representados foram o centro do bairro e a praça, esta última percebida a partir da comparação entre seu passado (como ambiente de intensa convivência) e seu presente (com diminuição significativa de frequentadores). Por sua vez, os marcos indicados foram basicamente elementos que, por suas características peculiares, podem orientar trajetos, que nem sempre agradavam aos participantes. Entre os marcos indicados sobressaíram os prédios escolares, o morro, a maré, e estabelecimentos comerciais (lan house, padaria, lanchonete). Tanto nos desenhos (diários) quanto nas entrevistas, os marcos foram associados a odores ("a maré fede"), à idade dos edifícios ("aqui é conhecido como colégio velho"), à escala ("daqui dá pra ver o pôr-dosol") e ao contraste figura/fundo (quadra em reforma, e outro local utilizado para partidas de futebol nomeado como "barreiro", etc).

Os casos da maré e do morro são controversos, pois se trataram de espaços semelhantes à praça, e embora sejam marcos localizadores, costumam ser evitados.

B: O morro faz muito tempo que eu frequentei ele (...) P: O que é que tem lá no morro? B: Eu não sei se agora tem, tinha antes toda tarde essa hora assim, tinha uma pessoa jogando 
vôlei, jogando bola, até outro tipo de esporte, outras pessoas iam só pra apreciar mesmo o pôr do sol porque é muito bonito a vista de lá. P: Do morro dá pra ver o pôr do sol? B: É. É perfeito, é muito bonito. (Estudante do turno vespertino, feminino, 14 anos)

Os elementos espaciais destacados constituem uma rede de interdependência que pode conferir a consolidação de um espaço integrado e com características peculiares. "Esses outros elementos não apenas estruturam a região internamente, como também reforçam a identidade do todo, enriquecendo e aprofundando seu caráter" (Lynch, 2011, p.93). No entanto, sabe-se que para o caso do Guarapes, parte de sua extensão espacial não atrai convivência, passagem, e até mesmo são desconhecidos como parte de suas dimensões físicas. Isso pode ser notado tanto em demarcações realizadas nos diários com a representação gráfica dos locais e pontuações sobre atividades que realizam, por considerações feitas ao longo das entrevistas.

Assim, considerando as atividades e os locais onde são desenvolvidas, a permanência dos estudantes no ambiente escolar, além da localização de suas residências, majoritariamente concentradas no centro, indica uma localidade onde "as vias adquirem identidade e ritmo não só devido a sua forma, ou por seus pontos nodais, mas pelas regiões que atravessam, pelos limites ao longo dos quais avançam, e pelos marcos distribuídos em toda a sua extensão" (Lynch, 2011, p.94). Se de um lado tem-se um centro diferenciado por suas atratividades, conforme se distancia das vias onde estão situados os serviços públicos e o comércio, de outro, são formadas divisões. Por exemplo, por vezes a chamada "maré", é dita como o lugar dos pobres, e o centro ("aqui em cima" - "onde tem tudo"), uma porção mais elevada do relevo na qual está situada a escola, a parte de maior convivência. Existem espaços considerados distantes da escola pelos participantes, cujo acesso por meio de caminhada dura entre 5 e 10 minutos (distância até a praça, por exemplo). Um dos casos, chegou a ser escolhido mais de um local: terminal de ônibus e morro.

Sobre os locais frequentados pelos participantes, a escola, a casa dos amigos e a quadra desportiva emergem como exemplos dos ambientes referidos, ainda que a última seja predominantemente mencionada por participantes do sexo masculino e a atividades definidas por alguns como de interesse apenas deste público (embora uma participante do sexo feminino seja integrante de grupo de futsal voltado para outras do mesmo sexo). No caso das atividades ilícitas, verifica-se que estas exercem influência na frequência reduzida a certos locais do bairro, associando-se ao uso de drogas, assassinatos, e riscos para saúde (mudanças na qualidade da água na maré, por 
exemplo). Apesar de reconhecerem a carência de segurança pública no bairro, isso não faz os participantes o definirem como "perigoso", e alguns explicitaram posicionamento divergente das opiniões das "pessoas de fora" que, segundo os estudantes, tendem a avaliar o local de modo negativo.

Portanto, a representação gráfica do bairro não abrangeu o todo de sua extensão física, mas os espaços de maior convívio e a frequência, assim como se deu a escolha dos locais de realização das entrevistas, embora em alguns casos tenha se conduzido a caminhar até à praça, e um deles até o morro, locais cuja frequência é referida como reduzida. Se por um lado, o procedimento apresentou limites às expressões dos estudantes (notadamente pela desistência de alguns em prosseguir da etapa dos diários, para as entrevistas), por outro, os ambientes desenhados foram aqueles cujos estudantes apresentam maior trânsito, especialmente aqueles comuns ao dia-adia do participante, e que estão situados com maior atratividade. Os limites entre os espaços, neste sentido, não alcançam as fronteiras com outras regiões administrativas, e a dificuldade na identificação de demarcadores por estudante que participaram do estudo, levantam as seguintes questões:

i) a não frequência em determinados setores limítrofes, como impeditivo do reconhecimento da demarcação física do bairro, em relação a outros;

ii) a disposição dos espaços de importância em uma porção física restrita do bairro, restringindo as representações a esta divisão;

iii) um espaço físico e sua imposição de forma, com consequências em suas percepção e relações, no qual vias, marcos e pontos nodais, não abrangem o todo do espaço físico do bairro;

iv) a disposição de vias que se estendem entre meios com características físicas muito diferentes do chamado "centro", a concentração dos pontos nodais onde se tem a maior densidade populacional e de áreas residenciais (assim como os marcos), e zonas limítrofes em termos de aparência física muito semelhantes em alguns casos (como por exemplo sua fronteira com o município de Macaíba), com poucos demarcadores físicos e populacionais. Segundo Lynch, “(...) Estamos continuamente tentando organizar nosso entorno, estruturá-lo e identificá-lo. Vários ambientes são mais ou menos receptivos a semelhante tratamento" (Lynch, 2011, p. 100).

As ponderações parciais sobre o bairro em geral mostram avaliações negativas (sobretudo com relação às suas divisões); enquanto que as avaliações globais são mais positivas no tocante ao local como um todo. Destacam-se as situações fora do bairro, pois os estudantes avaliam mais negativamente os outros locais (nitidamente externos ao Guarapes) e não se identificam com avaliações negativas do bairro 
feitas por outras pessoas. Além disso, os participantes apresentam dificuldades em representar o espaço físico do bairro como um todo, tendo em vista a pouca continuidade da principal via de acesso e a falta de clareza na delimitação de seus limites, culminando em restringir as descrições ao "centro" (onde está situada a escola). Os estudantes fazem pouca alusão à área da ZPA (não a reconhecendo como tal) e também parecem não captar as possíveis transformações que podem acontecer no bairro, caso seja efetivada a construção da ETE. Diante desse quadro, como garantir o alcance e os benefícios pretendidos para os grupos aos quais se destina?

Ainda que, neste estudo, não alcancemos a resposta para esse tipo de questão, os indícios relativos à percepção e aos limites do bairro geraram uma série de indagações sobre as relações dos grupos que convivem no local com os espaços existentes, nos levando a questionar o efetivo alcance de princípios e políticas públicas no campo da educação e voltadas para a promoção do acesso pleno à escola e à cidade.

\section{Considerações finais}

No que se refere ao espaço do bairro, um panorama de "distinção", não apenas é conferido por seus participantes, mas dispõe de localidade e características de fato distintas, materializadas no espaço físico. Assim, o centro do bairro (parte de cima) é mais desenvolvido, enquanto o Conjunto Dinarte Mariz (na parte de baixo, apelidado de "inferninho") e a maré (também localizada em parte baixa, tem o odor característico de mangue e, segundo os participantes, "fede", i.é, tem odor desagradável) são em alguns casos omitidos ou seu reconhecimento se dá por características não apreciadas pelos estudantes. Utilizando outras palavras, enquanto em relação a determinados espaços são percebidas características positivas e acontecimentos, outros locais não são reconhecidos ou tem sua existência/finalidade apenas parcialmente reconhecida. Estes são indícios de segregação no âmbito do bairro, refletindo a dicotomia centro/periferia presente na escala da cidade. Considerando que o local em estudo é ambiente cotidiano de crianças, adolescentes e jovens, a discussão das peculiaridades e implicações da inserção de ambientes escolares neste contexto urbano é essencial. Neste caso, um possível encaminhamento para próximos estudos, poderia partir da necessária atenção sobre a forma como os estudantes/moradores estabelecem vínculos com o ambiente, e entre ele e suas necessidades, bem como o modo de reconhecerem (ou não) a finalidade de uma paisagem/espaço.

De modo geral, a abordagem multimétodos adotada (conjugando diários e entrevistas) foi adequada à problemática e promoveu a 
coleta de informações essenciais à compreensão do tema, embora as limitações desta pesquisa também sejam reconhecidas, o que, paralelamente, permite a identificação de algumas perspectivas para a realização de novos estudos. Assim, por exemplo, diante da dificuldade de alguns estudantes para desenhar e traduzir seus conhecimentos sobre o bairro por meio de mapas, as entrevistas foram essenciais para desvendar o tema, embora, mesmo assim, alguns participantes tenham demonstrado inibição frente ao gravador de voz. Neste caso, outras questões dificultaram sua expressão, 0 que aponta a necessidade de investir em modos de minimizar esse tipo de obstáculos e propiciar um melhor alcance desse público.

Reforçamos, portanto, a importância de investigar como se dão as experiências de outros grupos (direta ou indiretamente) presentes na escola e no bairro, especialmente aqueles que ocupam ou frequentam os setores evitados pelos estudantes participantes deste estudo. A compreensão das características destes ambientes, das peculiaridades da cultura e valores ali cultivados, bem como das experiências e vínculos afetivos com o lugar daqueles que os ocupam provavelmente trariam mais olhares voltados para a compreensão das relações escola-bairro.

\section{Referências}

Albino, V. P. (2002). A semente da participação popular: adolescentes em Mãe Luíza.Dissertação de Mestrado. Universidade Federal do Rio Grande do Norte, Natal, RN, Brasil.

Altman, I., Chemers, M. (1980). Environmental Cognition and Perception. In I. Altman, M. Chemers. Culture and environment (pp. 42-71). California: Brooks/Cole Publishing Company

Associação Internacional de Cidades Educadoras (2009). Carta de Cidades Educadoras. Barcelona.

BBC (2011). Q\&A : Building Schools for the Future. Recuperado de: http://www. bbc.com/news/education- 10682980

Bonnes, M., Sechiarolli, G. (1995). Environmental Psychology and Psychological Tradition. In M. Bonnes, G.Sechiaroli. Environmental Psychology (pp. 20-33). California: Sage.

Bonnes, M., Sechiarolli, G. (1995). Knowing the environment. In M. Bonnes, G.Sechiaroli. Environmental Psychology (pp. 132-143). California: Sage.

Campos-de-Carvalho, M. I., Cavalcante, S., Nóbrega, L. M. A. (2010). Ambiente. In G. A Elali; S. Cavalcante, Temas Básicos em Psicologia Ambiental (28-43). Petrópolis: Vozes.

Conselho Nacional de Saúde (2012). Resolução 446/12 de 12 de dezembro de 2012. Diretrizes e normas regulamentadoras de 
pesquisas envolvendo seres humanos. Recuperado de: http: // www. propesq. ufrn. br/documento. php?id=109988775.

Faria, A. B. G. (2011). O pátio escolar como ter[ritó]rio [de passagem] entre a escola e a cidade. In: G. A. N. Azevedo, P. A. Rheingantz, V. R. Tângari (Orgs), O lugar do pátio escolar no sistema de espaços livres: uso, forma e apropriação (pp. 3544). FAPERJ , UFRJ , FAU, PROARQ.

Flick, U. (2009). An introduction to qualitative research. Londres: Sage.

Gaskell, G. (2002). Entrevistas individuais e grupais. In M. W. Bauer, e G. Gaskell, G. (Orgs.). Pesquisa Qualitativa com Texto, Imagem e Som: um manual prático (pp. 64-89). Petrópolis: Editora Vozes.

Góis, C. W. de L. (2007). Capítulo 6 - Técnicas de Facilitação. In C. W. de L. Góis Saúde comunitária pensar e fazer (pp. 185-197). São Paulo: Hucitec.

Gump, P. V. (1978). School Environments. In J. F. Wohlwill \& I. Altman (Orgs), Human and behavior: Vol. 3. Children and the environment (pp. 131-169). New York: Plenum Press.

Günther, H., Elali, G. A., Pinheiro, J. Q. (2008). A abordagem Multimétodos em Estudos Pessoa-Ambiente: Características, Definições e Implicações. In J. Q. Pinheiro \& H. Günther (Orgs.), Métodos de Pesquisa nos Estudos Pessoa-Ambiente (pp. 369-396). São Paulo: Casa do Psicólogo.

Günther, I. A., Nepomuceno, G. M., Spehar, M. C., Günther, H. (2003). Lugares favoritos de adolescentes no Distrito Federal. Estudos de Psicologia, 8(2), 299-308. Recuperado de <http://www.scielo.br/pdf/epsic/v8n2/19046. pdf>

Hynek, A. (1985). Environmental Perception. Scripta Fa. Sci. Nat. Univ. Purk. Brun., 15(3),171-180.

Kuhnen, A., Higuchi, M. I. G. (2011). Percepção Ambiental. In G. A. Elali, S. Cavalcante (Orgs.). Temas Básicos em Psicologia Ambiental (pp. 250-289). Petrópolis: Vozes.

Leiringer, R., Caderlino, P. (2011). Schools for the twenty-firdt century: school design and educational transformation. British Educational Research Journal, 6, pp. 915-934. Recuperado de: <https://www.researchgate.net/publication/233127213_School s_for_the_twenty-

first_century_School_design_and_educational_transformation>

Lynch, K. (2011). A imagem da cidade (3 ed., J. L. Camargo, trad.). São Paulo: Martins Fontes. (Texto original publicado em 1960)

Ministério da Educação (2013). Diretrizes Curriculares Nacionais da Educação Básica. Recuperado de: $<$ http://portal.mec.gov.br/index.php?option=com_content\&vie $\mathrm{w}=$ article\&id $=293 \&$ I temid $=810>$ 
Ministério da Educação (2013). Diretrizes Curriculares Nacionais para o Ensino Fundamental de 9 anos. Recuperado de: $<$ http://portal.mec.gov.br/index.php?option=com_content\&vie $\mathrm{w}=$ article\&id $=293 \&$ lemid $=810>$

Ministério da Educação (2014). Manual Operacional de Educação Integral. Recuperado de: <http://portal.mec.gov.br/index.php?option=com_content\&vie $\mathrm{w}=$ article\&id $=1669$ 0\&l temid $=1113>$

Ministério da Educação (2014a). Manual Operacional de Educação Integral. Recuperado de: <http://portal.mec.gov.br/index.php?option=com_content\&vie $\mathrm{w}=$ article\&id $=1669$ 0\&l temid $=1113>$

Ministério da Educação (2014b). Manual Operacional de Educação Integral. Recuperado de: <http://portal.mec.gov.br/index.php?option=com_content\&vie $\mathrm{w}=$ article\&id $=1669$ 0\&l temid $=1113>$

Ministério da Educação (2014c). Planejando a Próxima Década Conhecendo as 20 metas do Plano Nacional de Educação. Recuperado de: <http://pne.mec.gov.br/pdf/pne_conhecendo_20_metas.pdf>. Acesso em: 21 set. 2014.

Moreno, G. G. (2010). Jovens e experiência social na educação de jovens e adultos. (Dissertação de mestrado, Universidade de São Paulo, São Paulo).

Oliveira, L. M. A. N. de. (2016). O olhar dos estudantes sobre a relação escola-bairro: um estudo no Guarapes, Natal-RN. (Dissertação de Mestrado, Universidade Federal do Rio Grande do Norte, Natal).

Pinheiro, J. Q., Elali, G. A., Azevedo, A. V. M., Farias, B. C. G., Costa, M. C., Andrade, S. S. (2008). Diários pessoais como técnica de coleta de dados em estudos sobre as relações pessoaambiente. In J. Q. Pinheiro \& H. Günther (Orgs) Métodos de Pesquisa nos Estudos Pessoa-Ambiente (281-312). São Paulo: Casa do Psicólogo.

Prefeitura Municipal do Natal. Anuário dos Bairros do Município no Natal, RN. Natal, PMN, 2012.

Rivlin, L. G., Weinstein, C. S. (1984). Educational issues, school settings, and environmental psychology. Journal of Environmental Psychology, 4, 347-364.

Santos, N. (2002). Escola Pública e Comunidade Relações em D'Obras. Tese de Doutorado, Universidade Federal do Rio Grande do Sul, Porto Alegre, RS, Brasil.

Secretaria Municipal de Meio Ambiente e Urbanismo (2015). Natal Anuário. Natal: Autor. Recuperado de <http://r.search. yahoo.com/_ylt=A0LEVr9I N3dX5GAAWosf7At. ;_ylu=X3oDMTBybnV2cXQwBHNIYwNzcgRwb3MDMgRjb2xvA2J 
mMQR2dGIKAw--

$/ R V=2 / R E=1467459528 / R O=10 / R U=h t t p s \% 3 a \% 2 f \% 2$ fnatal. $r$. gov. br\% 2fsemurb\% 2fpaginas\% 2ffile\% 2fAnuarios\%2fAnuario_2 015. pdf $/ \mathrm{RK}=0 / \mathrm{RS}=\mathrm{CQAqdc} 8 \mathrm{VWOrG8diu40KeBrZGgjg->}$

Siegel, A. W., Kirasic, K. C. \& White, R. V. (1978). Stalking the elusive cognitive map: the development of childeren's representations of geographic space. In J. F. Wohlwill \& I. Altman (Orgs), Human and behavior: Vol. 3. Children and the environment (pp. 223-257). New York: Plenum Press.

Silva, H. L. da. (2009). Sentidos de uma pedagogia musical na escola: um estudo de caso na Escola Aberta Chapéu do Sol, Porto Alegre, RS. (Tese de Doutorado, Universidade Federal do Rio Grande do Sul, Porto Alegre).

Singer, H. (2015), Territórios Educativos: Vol. 2. Experiências em diálogo com o Bairro-Escola. São Paulo: Moderna.

Stoco, S., Almeida, L. C. (2011). Escolas municipais de Campinas e vulnerabilidade sócio demográfica: primeiras aproximações. Revista Brasileira de Educação, (16)48, 663-814.

Stokols, D. (1978). Environmental Psychology. Annual Review of Psychology, 29, 253-295.

Tuan, Yi-Fu (1980). Topofilia: Um estudo da percepção, atitudes e valores do meio ambiente. Rio de Janeiro: DIFEL/Difusão Editorial S. A.

\section{Endereço para correspondência \\ Lorena Macêdo A. N. de Oliveira}

Rua 21 de abril, 32, Boa Esperança, CEP 59140-390, Parnamirim - RN, Brasil

Endereço eletrônico: lorenandrade_neves@hotmail.com

Larissa Maria de Menezes Costā

Rua do J uritis, 8, Nova Parnamirim, CEP 59150-210, Parnamirim - RN, Brasil

Endereço eletrônico: larimameco@gmail.com

Gleice Azambuja Elali

Av. Getúlio Vargas, 782/1101, Petrópolis, CEP 59012-360, Natal - RN, Brasil

Endereço eletrônico: gleiceae@gmail.com

Recebido em: 13/07/2016

Reformulado em: 20/05/2018

Aceito em: $31 / 08 / 2018$

\section{Notas}

* Psicóloga e Mestre em Psicologia

** Psicóloga.

*** Professora da Universidade Federal do Rio Grande do Norte.

As autoras declaram que esse trabalho está vinculado à Universidade Federal do Rio Grande do Norte (UFRN) e foi parcialmente financiado pelo Conselho Nacional de Desenvolvimento Científico e Tecnológico (CNPq) / Coordenação de Aperfeiçoamento de Pessoal de Nível Superior (CAPES) / Brasil - Financiamento 
Code 001 referente à bolsa de Mestrado da primeira autora, bolsa PIBIC da segunda e bolsa de Produtividade em Pesquisa da terceira. Asseguram, ainda, que não foram omitidas quaisquer ligações a instituições comerciais ou políticas, e não existem quaisquer conflitos de interesse com os resultados apresentados.

Este artigo de revista Estudos e Pesquisas em Psicologia é licenciado sob uma Licença Creative Commons Atribuição-Não Comercial 3.0 Não Adaptada. 